\title{
Mechanically Induced Waves in Metallic Glass Foils
}

\author{
N. T. Panagiotopoulos ${ }^{1}$, M. A. Yousfi ${ }^{1}$, K. Georgarakis ${ }^{1,2}$, A. R. Yavari $^{1}$ \\ ${ }^{1}$ EURONANO, SIMaP, Grenoble INP-CNRS-UJF, BP 75, 38402 Saint Martin d'Hères, France \\ ${ }^{2}$ WPI-AIMR, Tohoku University, Sendai 980-8577, Japan
}

Corresponding author: basset.yousfi@gmail.com; euronano@minatec.inpg.fr

\begin{abstract}
The response of vitrified metallic arc foils under normal load is studied. Application of normal load on an initial arc shaped vitrified metallic foil is followed by multiplication of the initial arc. A sinusoidal mathematical expression can be used for the description of the produced harmonic undulations. The number of the formed waves increases as the displacement increases. Therefore, this undulatory behavior of the vitrified foils can be exploited as a flat spring with multiple spring constants. For comparison crystalline foils were tested. The enormous elastic region of vitrified alloys allows this undulatory response to occur extensively while plastic deformation is unavoidable when crystalline foils are used. Exploiting the metallic glass characteristics, the predefined extrema positions of the formed undulations and the mechanical characteristics of the vitrified foils a new type of electromechanical switch is suggested.
\end{abstract}

Keywords: Vitrified metallic foils, undulatory response, flat springs, metallic glasses, buckling, electromechanical switch

\section{Introduction}

Vitrified metallic alloys, as a relatively young class of material, are produced in bulk and foil forms. Mechanical tests such as compression, tension and bending have been conducted to characterize bulk vitrified alloys revealing their extremely high strength (2-5 GPa), large elastic deformation $(\sim 2 \%)$, excellent superplastic formability in the supercooled liquid region $[1,2]$ and good wear and corrosion resistance [3]. A combination of such properties led this new class of engineering materials to be applied in many technological fields such as MEMS (MicroElectro-Mechanical Systems) and NEMS (Nano-Electro-Mechanical Systems) [4-8]. Due to their high elastic limit, nearly ten times higher than conventional crystalline materials ( $\sim 0.2 \%)$, vitrified alloys have been reported as material for the production of springs with enhanced properties [9]. 
Metallic and semiconducting foils, thin films and membranes in wavy and buckled forms are widely produced mainly using flexible substrates either after substrate stress release or by lithography [10-15]. Important role for the production of the wavy patterns play the thermomechanical properties of both buckled materials and substrate [16]. Recent research work has shown the ability to use vitrified foils for thermomecanical wavy shaping without thermal embrittlement [17].

In this work we report for the first time a dynamic reversible undulatory response of arc shaped vitrified foils under normal load. Utilizing this reversible behavior, a novel flat spring with multiple spring constants is proposed for the production of a new type of electromechanical switches.

\section{Experimental details}

Vitrified $\mathrm{Fe}_{90.65} \mathrm{~B}_{3.9} \mathrm{Cr}_{2.75} \mathrm{Si}_{2.7}$ (at\%) foils with nominal thickness of $19 \mu \mathrm{m}$ and width of $25 \mathrm{~mm}$ were purchased from Metglas (part number: 2605S3A). Crystalline titanium and stainless steel foils were purchased from Alfa Aesar with nominal thickness of $12.7 \mu \mathrm{m}$ and $25 \mu \mathrm{m}$, respectively. A $50 \mu \mathrm{m}$ thick commercial brass foil of was also used.

A flat plate was used for the fixation and the formation of the initial arc shape in the foils, fig. 1a. Normal load was applied on the top of the arc surface using a Tinius Olsen H10kS compression machine. Snapshots were taken using an Allied Vision Technologies Prosilica GX6600 CCD camera, equipped with an EXSIGMA macro lens. Measured parameters were the arc amplitude $\left(h_{i}, i=1,2, \ldots, n\right)$ and the arc curvature radius $\left(R_{i}, i=1,2,3, . ., n\right)$ of each arc. Indices $i=1$ and $i=n$ refer to the initial arc form, when no load is applied, and to the maximum number of the formed arcs produced during the application of normal load, respectively. The state in which the less applied normal load was needed for the formation of different number of waves was used for the measurements of the amplitude $h_{i}$ and the curvature radius $R_{i}$. The horizontal boundaries distance $(L)$ was defined as the distance between the fixation points of the foil on the flat plate, fig. $1 \mathrm{~b}$.

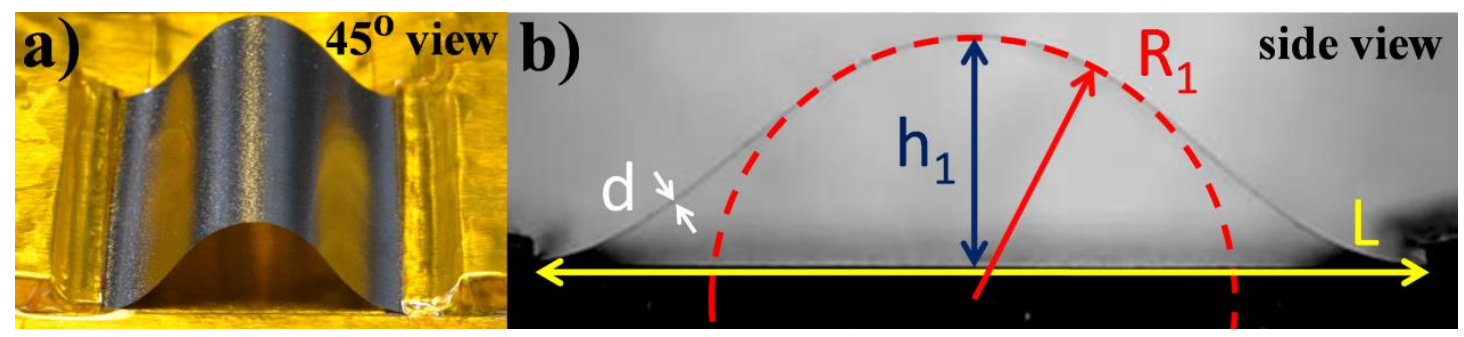

Figure1: Initial arc shaped vitrified foil before application of normal load in a) $45^{\circ}$ view and b) side view and the measured parameters. 


\section{Results and discussion}

Normal load was applied on the top surface of an arc shaped vitrified foil, fig 1 . As the load was progressively increasing a sinusoidal undulatory response of the initial arc was observed by increasing the number of the formed waves, fig. 2 .

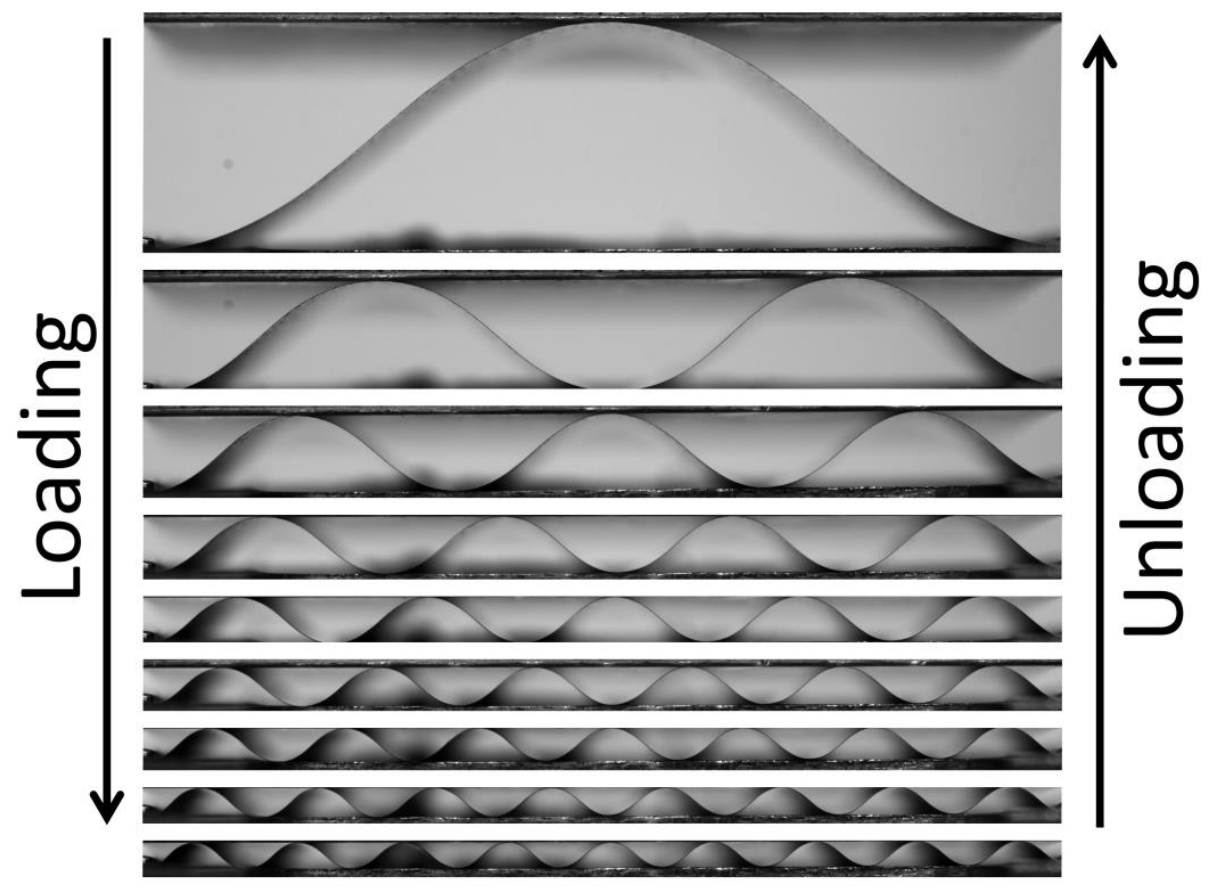

Figure 2: Harmonic undulatory response of arc shaped vitrified foil. From top to bottom, formation of the initial arc up to the formation of nine waves after normal load application.

Successive undulatory response could be obtained only when the $h_{1} / L$ ratio fulfill the inequality

$$
\frac{h_{1}}{L} \leq \frac{1}{2}
$$

where $h_{l}$ is the initial amplitude of the arc and $L$ the horizontal boundary conditions.

From the classic wave theory, it is well known that for a restricted wave, stationary oscillations can be produced. Using simple formulations for standing waves [18], it was found that the observed undulatory response of the vitrified foil under normal load can be well described by:

$y^{2}(x)=A \sin ^{2}\left(n \frac{2 \pi}{\lambda_{\text {fundamental }}} x\right)$ 
where $\mathrm{A}$ is a constant which equals to the arc amplitude $\mathrm{h}_{\mathrm{i}}, n$ is the harmonic number of the formed waves and $\lambda_{\text {fundamental }}$ is the fundamental wavelength. Fig. 3 shows a representative mathematical description of the formed waves.

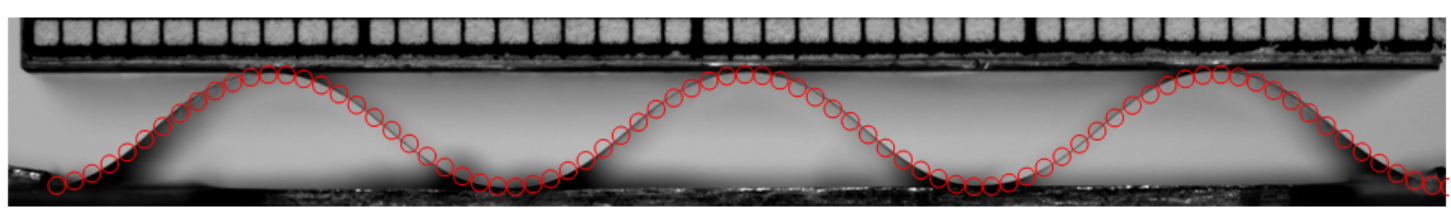

Figure 3: Experimental and calculated (red open cycles) undulatory response of vitrified foil under normal load.

The observed undulatory behavior which originates from the generation of new arcs as the load increases is a reversible procedure. After load release the vitrified foil returns to its initial arc shape gradually by minimizing the number of arcs in the formed waves. For that to be achieved, the maximum strain in the vitrified foil must not exceed the elastic limit, which for metallic glasses is reached at about $2 \%$ of deformation [19]. The strain in the foil takes maximum values (locally) around the arcs. According to Aljerf et al [17] the maximum strain $\varepsilon$ around the arcs can be approximated by: $\varepsilon=\mathrm{d} / 2 \mathrm{R}$ where $\mathrm{d}$ is the thickness of the foil and $\mathrm{R}$ is the radius of curvature. Thus, for a vitrified foil with maximum elastic strain $\varepsilon_{\text {elastic max }}$ of about $2 \%$, the radius of curvature should remain higher than a critical value $\mathrm{R}_{\min }$ in order to avoid local plastic deformation in the foil :

$$
R>R_{\min }=\frac{d}{2 \varepsilon_{\text {elastic } \max }} \approx 25 d
$$

where $d$ is the thickness of the foil.

For constant horizontal boundary distance and the same number of waves, the curvature radius decreases as the initial amplitude $\mathrm{h}_{1}$ increases. It is also noted that, as the initial amplitude decreases the maximum number of harmonic undulations in the formed waves decreases. Fig. 4 presents the strain that develops in the wavy foils as a function of the number of harmonic undulations. The local strain was estimated using the equation $\varepsilon=d / 2 R_{i}$ [17], where $d$ is the thickness of the foil and $R_{i}$ the arc curvature radius $\left(R_{i}, i=1,2,3, \ldots, n\right)$. Data are shown for foils with $\mathrm{L}=20 \mathrm{~mm}$ and different initial arc amplitudes. It can be observed that for all the examined cases the strain remains below the elastic limit of $2 \%$. 


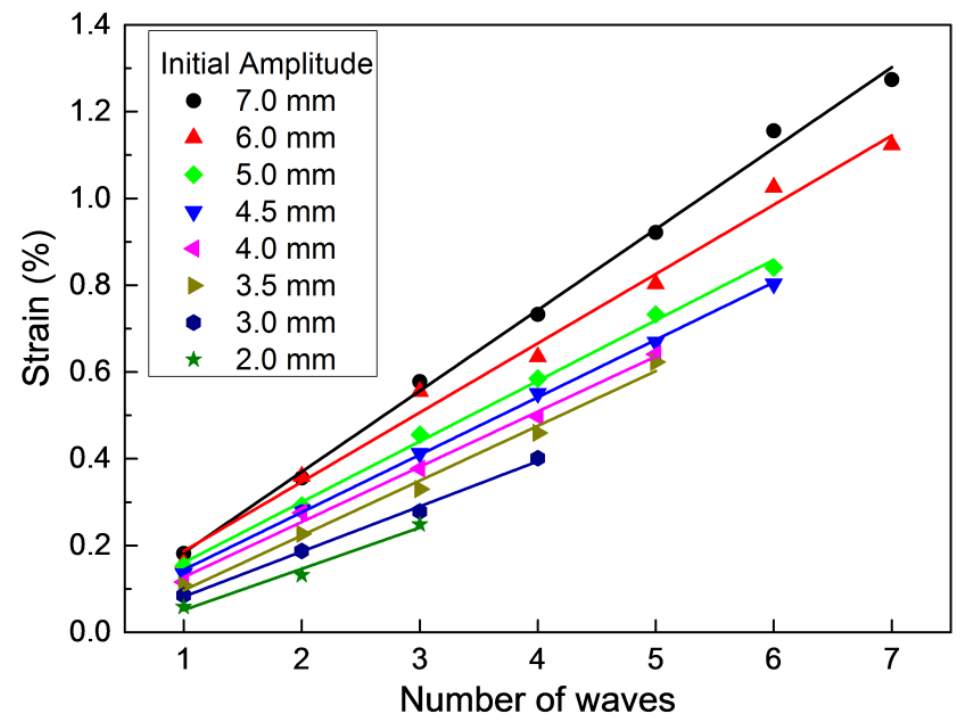

Figure 4: Strain that develops in the wavy foils versus the number of the waves for different initial amplitudes. $\mathrm{L}=20 \mathrm{~mm}$ and foil thickness $=19 \mu \mathrm{m}$.

Using a compression testing device the arc shaped foils were loaded and unloaded in the elastic region in order to obtain a quantitative load-displacement analysis of the undulatory response of vitrified foils. Fig. 5a shows the evolution of the load versus displacement during loading and unloading for an initial arc shaped vitrified foil with $L=20 \mathrm{~mm}$ and $h_{l}=5 \mathrm{~mm}$. Different paths were observed during compression and decompression (unloading) solicitation, fig. 5a. During loading, the vitrified foil is subjected to compressive stresses that force the foil to buckle and form an additional arc at specific values of load (or displacement) thus leading to the observed undulatory behavior. During unloading the crosshead of the compression device progressively returns to its initial position and the foil elastically recovers its initial shape. As the applied load increases, segments of the load-displacement curve with constant slopes can be observed between two successive events of arc formation. A small but sharp decrease of load occurs at the moment a new arc is forming. As the number of the formed waves increases, for the formation of the $n+1$ wave higher load values are needed, while the displacement decreases. For each individual formed wave the load-displacement curve is linear until the transition to $n+1$ wave. The proportional coefficient can be attributed to a spring constant $(k)$ according to the Hooke's law. Different slopes correspond to different spring constants. Therefore, each formed wave with $\mathrm{n}$ maxima can be treated as an individual spring with its own physical characteristics. Snapshots and the calculated spring constants from the dynamic undulatory response of the vitrified foil during the compression tests are shown as insets in fig. 5a.

This undulatory behavior can be exploited as a spring with multiple spring constants. In such a multi- $k$ flat spring the $k$ values are strongly correlated with the initial horizontal boundary 
conditions and the initial amplitude $h_{l}$. Fig. 5b shows the calculated spring constants from the compression tests versus the number of waves for four different horizontal boundary lengths (L). In all cases the initial amplitude was $h_{l}=\mathrm{L} / 4$, for $L=20,30,40,50 \mathrm{~mm}$. Same spring constants values were calculated during loading and unloading for each individual horizontal boundary condition. The calculated spring constants vary within the range from $0.7 \mathrm{~N} / \mathrm{mm}$ to $450 \mathrm{~N} / \mathrm{mm}$ depending on the number of the formed waves, the initial amplitude $h_{l}$ and the horizontal boundary conditions $L$. Fig. 5c shows the maximum applied normal load on a wavy foil with $n_{i}$ sinusoidal undulations (just before the formation of the $n_{i}+1$ undulation) versus the number of undulations. Results are presented for foils with different horizontal boundary lengths $L=20,30,40,50 \mathrm{~mm}$ while the initial arc amplitude obeys the ratio $h_{l}=\mathrm{L} / 4$. The load is seen to increase exponentially with the number of undulations in the wavy patterns. This increase is more rapid for foils with smaller horizontal boundary lengths L. The working load range of a wavy vitrified foil can increase with increasing the thickness and/or the width of the foil.

In order to evaluate the extent to which crystalline metals can exhibit undulatory behavior, similar tests were performed using crystalline foils with higher, similar and lower thickness than that of the vitrified foil $(19 \mu \mathrm{m})$. More specifically, a $50 \mu \mathrm{m}$ thick brass, a $25 \mu \mathrm{m}$ thick stainless steel and a $12.7 \mu \mathrm{m}$ titanium foil were used. For all crystalline foils, plastic deformation was observed in earlier stages, due to their lower elastic strain limit of about $0.2 \%$. Among the crystalline materials, the thinner titanium foil (12.7 $\mu \mathrm{m}$ thickness) was observed to exhibit the best undulatory response due to the lower levels of local strain that are developed for the same radius of curvature (or displacement) as suggested by Eq. (3). Plastic deformation occurred in the thinner titanium foil after the formation of two sinusoidal undulations whereas for the thicker foils (stainless steel and brass) plastic deformation occurred without any multiplication of the initial arc, fig. $5 c$, indicating that the undulatory behaviour of crystalline foils is quite limited. 

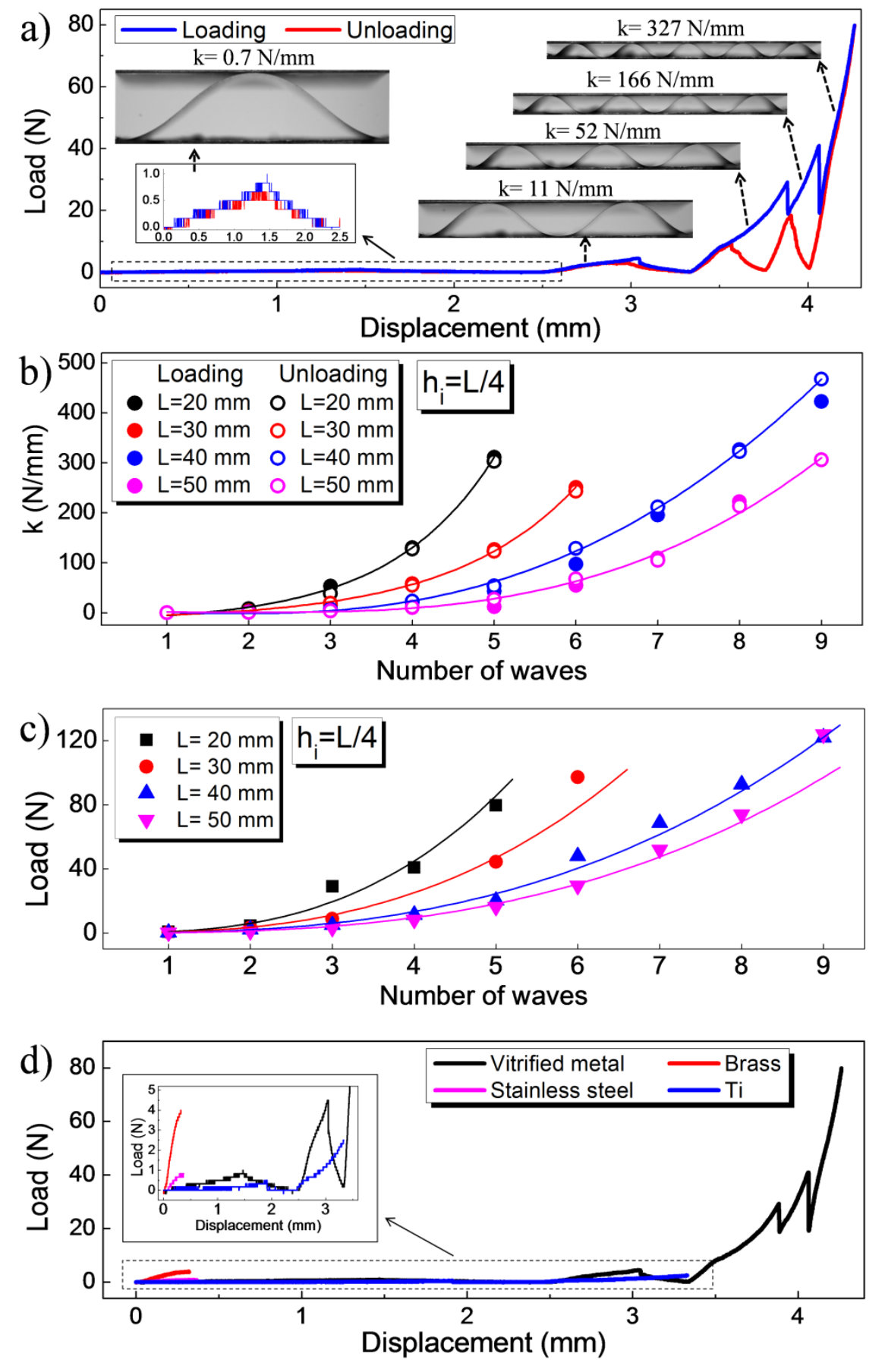

Figure 5: Mechanical undulatory behavior of vitrified and crystalline foils: a) Load vs displacement during loading and unloading for a vitrified foil with $L=20, h_{1}=5$ and width $w=25 \mathrm{~mm}$. Snapshots of the undulatory behavior and the calculated spring constants are shown in the inset. b) Calculated spring constants in compression and decompression (unloading) for different horizontal boundary lengths and initial amplitudes versus the number of waves. c) Maximum applied normal load on a wavy foil with $n_{i}$ sinusoidal undulations (just before the formation of the $n_{i}+1$ undulation) versus the number of undulations $\mathrm{n}_{\mathrm{i}}$, d) Limitations of the undulatory behavior of brass, titanium and stainless steel crystalline foils in comparison with a vitrified metallic foil. 
The results confirm the superior elastic performance of vitrified foils which leads to the observed undulatory behavior. As the number of harmonic undulations in the formed waves increases, springs with higher $k$ values are formed. Therefore, the proposed novel flat spring can be used twofold. In the simplest configuration, a spring with specific constant $k$ can be chosen. In a more sophisticated configuration, the multi- $k$ spring behavior can be exploited.

As shown in fig. 3 and Eq. (2), the extrema positions of the undulatory response occur in predefined positions which are independent from the initial amplitude $h_{l}$. A non-conductive plate can be used for the foil fixation on which electrical contacts are engraved at the extrema positions. Thus, electrical circuits can be integrated and electric current can flow through the vitrified metallic foil. For simplicity, the minima positions were used. Fig. $6 \mathrm{a}, 6 \mathrm{c}$ and $6 \mathrm{e}$ show a schematic top view of three different and individual electrical circuits that close successively as the applied normal load increases and the $n+1$ wave forms. Bright and dark areas on the foil surface correspond to maxima and minima positions, respectively. Using a simple $4.5 \mathrm{Volt}$ battery as electric current source, a different combination of LEDs is lighting on once another wave is formed, connecting the foil to a different closed circuit as seen in the side view pictures of figures $6 \mathrm{~b}, 6 \mathrm{~d}, 6 \mathrm{f}$. A simple example of the operation of such a device can be seen in the supplementary video 1 .

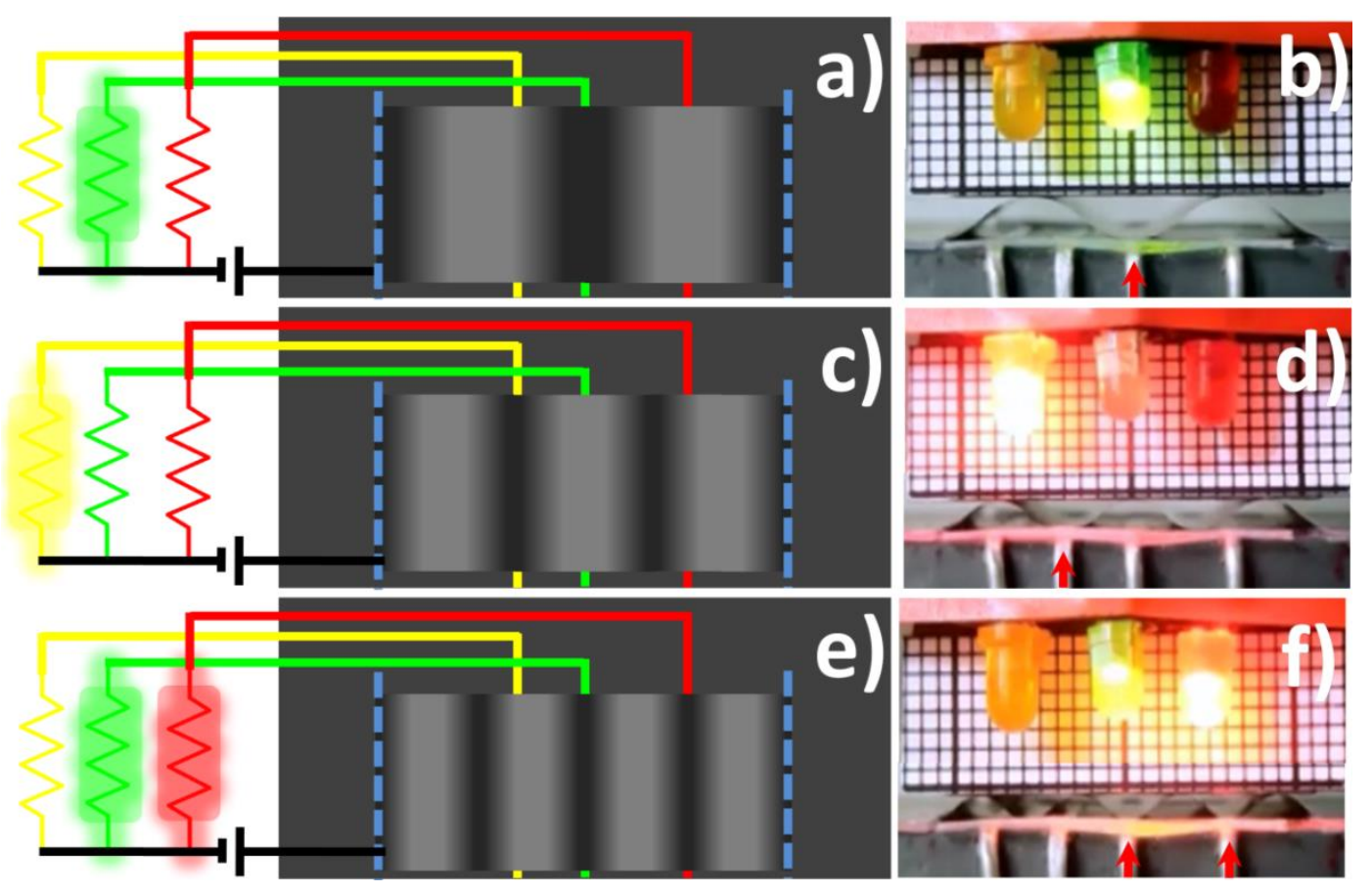

Figure 6: Integrated electrical circuits due to the undulatory behavior of vitrified metallic foil. a), c), e) Schematic top view and b), d), f) side view snapshots. 
Another device design was constructed in which the vitrified foil was used as an electromechanical switch due to its undulatory response under normal load. The vitrified foil and the integration circuits are the same as previously described. A "free to roll" plate was used to apply the normal load to the vitrified foil using a linear actuator. The linear actuator and the "free to roll" plate were not attached to each other. As the above described electrical circuits were integrated, electrical signal was sent to an electronic platform (Adruino board) used for the control of the movement of the linear actuator. The electromechanical switch was able to operate between 2 and 5 waves as shown in the sketch of fig. 7 . When 5 waves were formed, an electrical signal was giving the command to the linear actuator to stop applying the load and to pull back. The vitrified foil, acting as a spring, was pushing back the "free to roll" plate and simultaneously was decreasing its number of waves. Thereafter, when two waves were formed, a different electric circuit was connected and a new signal was send to the linear actuator to start applying load again. Supplementary video 2 shows a simple application of this concept. In this repeatable process, any sequence of numbers of waves can be selected, giving the opportunity to the user to choose from a wide range of load-displacement and spring constant values.

\section{a)}

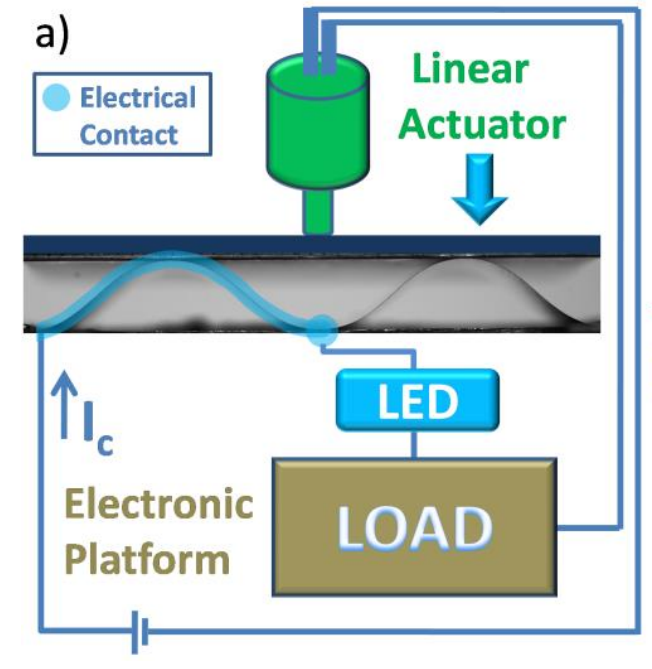

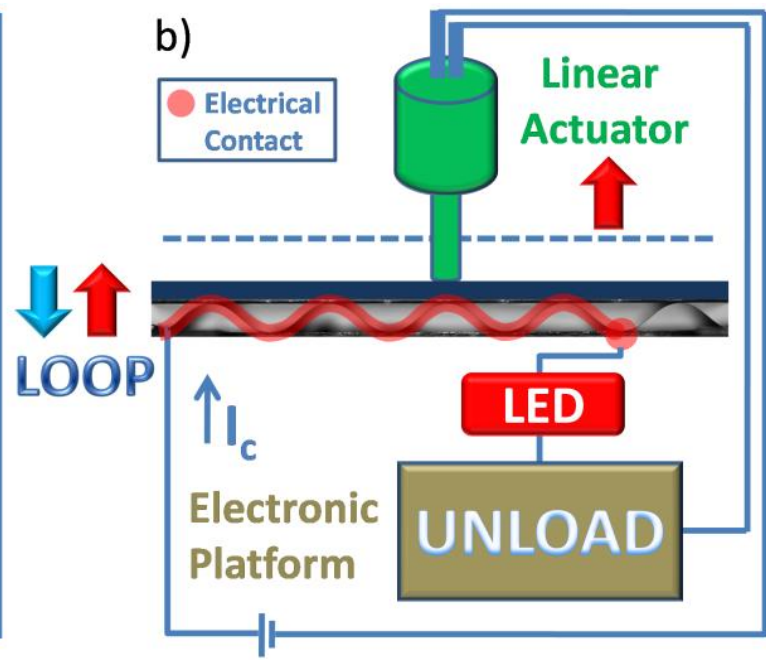

Figure 7: The concept of an electromechanical switch utilizing the undulatory behavior of the vitrified foils: a) At the initial stage the wavy foil connects to an electric circuit a specific position and the electronic platform (Arduino board) sends a signal to the linear actuator to move forward and apply load to the foil thus increasing the number of undulations; b) When the undulations increase to a predefined number, the foil connects to a different electric circuit and the electronic platform sends a signal to the actuator to retract allowing the foil to elastically recover to the initial stage. 


\section{Conclusions}

The undulatory behavior of an arc shaped vitrified metallic foil under normal load was studied. It was found that as the load increases the response of the initially arc shaped vitrified metallic foil is to deform elastically creating harmonic wavy patterns. The produced wavy patterns can be described by a sinusoidal mathematic expression according to the classical wave theory. Due to the high elastic region of vitrified metallic foils this reversible undulatory behavior can be obtained for a high number of new formed waves contrary to the case of crystalline foils. The combination of the elastic properties and the undulatory response of the vitrified alloys makes them strong candidates for the use as flat springs with multiple spring constants. The number of the formed waves and the range of the obtained spring constants depend on the geometrical parameters of the initial arc. Furthermore, exploiting the metallic character and the mechanical properties of the vitrified metallic foils a novel electromechanical switch is proposed.

\section{Acknowledgements}

N.T.P. acknowledges the financial support of the European ITN Network project \#607080 (VitriMetTech). This work was funded by the ANR project "New vitrified springs". K.G. acknowledges support from JSPS KAKENHI (Grant \#15K18201).

\section{References}

[1] Kim WJ, Lee JB. and Jeong HG. Superplastic gas pressure forming of $\mathrm{Zr}_{65} \mathrm{Al}_{10} \mathrm{Ni}_{10} \mathrm{Cu}_{15}$ metallic glass sheets fabricated by squeeze mold casting. Mater. Sci. Eng. 2006; A 428: 205210.

[2] Schroers J, Nguyen T, O' Keeffe S and Desai A. Thermoplastic forming of bulk metallic glass-Applications for MEMS and microstructure fabrication. Mater. Sci. Eng. A 2007; 449451:898-902.

[3] Pang SJ, Zhang T, Asami K, Inoue A. Synthesis of Fe-Cr-Mo-C-B-P bulk metallic glasses with high corrosion resistance. Acta Mater. 2002;50:489-497.

[4] Peker A and Johnson WL. A highly processable metallic glass: $\mathrm{Zr}_{1.2} \mathrm{Ti}_{13.8} \mathrm{Cu}_{12.5} \mathrm{Ni}_{10.0} \mathrm{Be}_{22.5}$. Appl. Phys. Lett. 1993;63: 2342-2344.

[5] Inoue A. Stabilization of metallic supercooled liquid and bulk amorphous alloys. Acta Mater. 2000;48: 279-306.

[6] Wang WH, Dong C, and Shek CH. Bulk metallic glasses. Mater. Sci. Eng. R. 2004; 44: 4589.

[7] Nguyen DS, Halvorsen E, Jensen GU and Vogl A. Fabrication and characterization of awideband MEMS energy harvester utilizing nonlinear springs. J. Micromech.Microeng. 2010; 20: 125009 . 
[8] Grech D, Kiang KS, Zekonyte J, Stolz M, Wood RJK, Chong HMH. Highly linear and large spring deflection characteristics of a Quasi-Concertina MEMS device. Microel. Eng. 2014;119: 75-78.

[9] Sona K, Soejima H, Nishiyama N, Wang XM, Inoue A. Process development of metallic glass wires by a groove quenching technique for production of coil springs. Mater. Sci. Eng. A 2007; 449-451: 248-252.

[10] Lu N, Yang S. Mechanics for stretchable sensors. Curr. Opin. Solid State Mater. Sci. 2015; 19:149-159.

[11] Wang S, Song J, Kim DH, Huang Y, Rogers JA. Local versus global buckling of thin films on elastomeric substrates. Appl. Phys. Lett. 2008;93:023126.

[12] Li Z, Wang Y, Xiao J. Mechanics of curvilinear electronics and optoelectronics. Curr. Opin. Solid State Mater. Sci. 2015;19:171-189.

[13] Zhang Y, Huang Y, Rogers JA. Mechanics of stretchable batteries and supercapacitors. Curr. Opin. Solid State Mater. Sci. 2015; 19:190-199.

[14] Ma T, Liang H, Chen G, Poon B, Jiang H, Yu H. Micro-strain sensing using wrinkled stiff thin films on soft substrates as tunable optical grating. Opt. Express 2013; 21:11994-12001.

[15] Choi WM, Song J, Khang DY, JiangH, Huang YY, Rogers JA. Biaxially Stretchable "Wavy" Silicon Nanomembranes. Nano Lett. 2007; 7:1655-1663.

[16] Lang W, Jakobs F, Tolstosheeva E, Sturm H, Ibragimov A, Kesel A, Lehmhus D, Dicke U. From embedded sensors to sensorial materials - The road to function scale integration. Sensor. Actuat. A-Phys. 2011;171:3-11.

[17] Aljerf M, Georgarakis K, Yavari AR. Shaping of metallic glasses by stress-annealing without thermal embrittlement. Acta Mater. 2011; 59: 3817-3824.

[18] D. M. Katz, Physics for Scientists and Engineers: Foundations and Connections, Advanced Edition, Cengage Learning, Boston, 2014

[19] Georgarakis K, Aljerf M, Li Y, LeMoulec A, Charlot F, Yavari AR, Chornokhvostenko K, Tabachnikova E, Evangelakis GA, Miracle D, Greer AL, Zhang T. Shear band melting and serrated flow in metallic glasses. Appl. Phys. Lett. 2008; 93: 031907. 
2015-10-29

\section{Mechanically induced waves in metallic glass foils}

\section{Panagiotopoulos, N. T.}

\section{Elsevier}

Panagiotopoulos NT, Yousfi MA, Georgarakis K, Yavari AR. (2016) Mechanically induced waves in metallic glass foils. Materials and Design, Volume 90, January 2016, pp. 1110-1114 https://doi.org/10.1016/j.matdes.2015.10.149

Downloaded from Cranfield Library Services E-Repository 